Terbit online pada laman web jurnal: http://jurnal.iaii.or.id

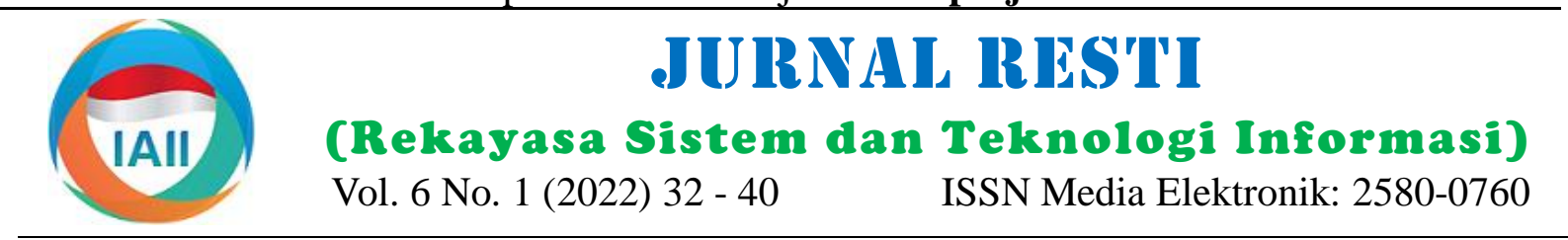

\title{
Monitoring dan Kendali Tegangan Jaringan Listrik Fase-tiga melalui Smartphone
}

\author{
Arief Goeritno ${ }^{1}$, Febby Hendryan ${ }^{2}$ \\ ${ }^{1}$ Program Studi Teknik Elektro, Fakultas Teknik dan Sains, Universitas Ibn Khaldun Bogor \\ ${ }^{2}$ CV Pendawa Inti Data, Jalan Jupiter S3/39A, Griya Bogor Raya, Katulampa, Bogor Timur, Kota Bogor 16144 \\ ${ }^{1}$ arief.goeritno@uika-bogor.ac.id, ${ }^{2}$ febbyhendryan@yahoo.com
}

\begin{abstract}
This paper describes the creation of a minimum system for monitoring and controlling the voltage on a three-phase electrical network. Making a minimum system based on the result of previous research that has been implemented in the forms of device assembly, programming, and performance measurement. The research objectives are (i) assembling the hardware and programming based on Arduino software version 1.8.10 and (ii) measuring the minimum system performance. The research method for achieving the objective of assembling a minimum system is carried out through integrated wiring as an effort to get the hardware achievement, while for programming is an effort to get the software achievement. The implementation of the research method for measuring the performance as an effort to get the achievements of hardware and software is carried out by giving the orders to activate the paths of each phase. The result of the assembly is the integration of the Arduino UNO R3 module, Ethernet Shield type of W5100, MikroTik RouterBoard, relay modules, and Android smartphone, while the results of the programming are compiling and uploading the syntax to the Arduino module and making applications in the .apk format for a smartphone. Performance measurements are carried out by activating conditions for the three phases of phase- $R$, phase$S$, and/or phase-T. The conclusion can be obtained, that the manufacture of a minimum system is appropriate for the fulfillment with respect to the presence of an electronic device for monitoring and controlling the voltage on a three-phase electrical network.
\end{abstract}

Keywords: electric voltage, a three-phase network, Ethernet shield, Arduino microcontroller, Android smartphone.

\begin{abstract}
Abstrak
Makalah ini merupakan penjabaran terkait pembuatan sistem minimum (minimum system) untuk pemantauan dan pengendalian tegangan listrik pada jaringan fase-tiga. Pembuatan sistem minimum didasarkan kepada hasil penelitian sebelumnya yang telah diimplementasikan dalam bentuk perakitan perangkat, pemrograman, dan pengukuran kinerja. Sasaran penelitian ini, yaitu (i) merakit dan memrogram perangkat keras berbantuan Arduino software versi 1.8.10 dan (ii) mengukur kinerja sistem minimum. Metode penelitian untuk pencapaian sasaran terhadap perakitan sebuah sistem minimum dilakukan melalui pengawatan terintegrasi sebagai upaya untuk ketercapaian secara perangkat keras, sedangkan pembuatan program merupakan upaya untuk ketercapaian secara perangkat lunak. Pelaksanaan metode penelitian untuk pengukuran kinerja sebagai upaya bentuk ketercapaian secara perangkat keras dan lunak, dilakukan melalui pemberian perintah untuk pengaktifan ketiga jalur fase. Hasil perakitan berupa pengintegrasian dari modul Arduino UNO R3, Ethernet Shield tipe W5100, MikroTik RouterBoard, modul relai, dan smartphone Android. Hasil pemrograman berupa compiling dan uploading sintaks ke modul Arduino dan pembuatan aplikasi format .apk untuk smartphone. Pengukuran kinerja dilakukan melalui pengaktifan kondisi untuk tiga-fase pada fase$\mathrm{R}$, fase-S, dan/atau fase-T. Berdasarkan hasil-hasil penelitian dapat disimpulkan, bahwa sistem minimum terpabrikasi telah sesuai untuk pemenuhan terkait dengan keberadaan perangkat elektronika yang digunakan untuk pemantauan dan pengendalian tegangan jaringan listrik fase-tiga.
\end{abstract}

Kata kunci: tegangan listrik, jaringan fase-tiga, Ethernet shield, mikrokontroler Arduino, smartphone Android.

\section{Pendahuluan}

Penelitian ini merupakan sebuah pilihan lain terhadap pemanfaatan jalur Internet melalui sebuah router, sehingga dapat dikatakan sebagai sebuah second opinion terhadap jalur komunikasi. Penelitian sebelumnya telah terimplementasikan dengan bantuan jaringan Internet melalui internal Wi-Fi [1]. Keberadaan sebuah kombinasi smartphone Android dan jaringan wireless berbasis protokol Internet dewasa ini telah menjadi keniscayaan [2,3]. Saat ini, keberadaan smartphone Android telah menjadi

Diterima Redaksi: 24-11-2021 | Selesai Revisi: 19-01-2022 | Diterbitkan Online: 01-02-2022 
powerful yang diperkuat dengan microprocessor (pemroses mikro) terkini [3]. Pengembangan teknologi dan perbaikan terus-menerus merupakan upaya untuk pemenuhan standar kehidupan masyarakat, kebutuhan otomasi, dan sistem kontrol rumah tinggal cerdas dan praktis [4]. Salah satu unit kendali yang menjadi bagian dari pengontrolan pada rumah tinggal pintar, yaitu pemantauan jaringan listrik melalui kondisi miniature circuit breaker (MCBs) berbantuan sejumlah komponen elektronika yang terkontrol melalui mikrokontroler [5,6] atau komputer personal [7]. Pembuatan sistem pengontrol sebagaimana penelitian-penelitian sebelumnya, dapat dilakukan melalui pabrikasi untuk keterbentukan sebuah modul elektronika [8-11] berbasis chip mikrokontroler ATmega328 [12] atau melalui pemanfaatan modul Arduino [13] untuk sejumlah sistem pengontrol [14-18]. Keberadaan modul pengontrol untuk pengoperasian analogi lampu pijar berbasis mekanisme kendali secara remote melalui jaringan Internet [19,20,1,21,22], merupakan upaya untuk penyelesaian alternatif pada penelitian ini.

Berpedoman kepada penjabaran latar belakang tersebut, sejumlah hasil penelitian sebelumnya untuk review terhadap keberadaan "state of the art" terkait dengan penelitian ini, yaitu keberadaan minimum system melalui keberhasilan jabat-tangan (handshaking) secara perangkat keras (hardware) dan perangkat lunak (software) yang berbentuk fisis rangkaian elektronika terintegrasi untuk pengendalian secara remote [19,20,1,21,22]. Keberhasilan handshaking secara hardware dilakukan melalui pengintegrasian sejumlah perangkat elektronika [19-22,1], sedangkan secara software dilakukan melalui (i) penyusunan struktur program berbasis Arduino IDE [23] dan aplikasi monitoring berbasis App Inventor pada komputer personal, (ii) pemasangan aplikasi monitoring pada smartphone Android [17,19,20,1] dengan sistem pengoperasian (Operating System, OS) mobile [24], dan (iii) pembuatan aplikasi untuk ditanamkan pada board Arduino UNO R3 dan smartphone Android melalui jaringan Internet [2,25]. Sejumlah hal itu digunakan keperluan pengendalian solenoid penggerak kunci [26], untuk pemantauan dan pengendalian beban listrik pada analogi instalasi listrik fase-tiga $[19,20,1]$.

Keberadaan komunikasi antara board Arduino dan telepon pintar (smartphone) dewasa ini sudah sangat mudah dan dapat dilakukan dengan banyak cara, salah satu cara praktis melalui penggunaan kabel USB dan aplikasi Android atau Android USB Host Application Programming Interface (API) [27], agar smartphone Android dapat saling bertukar data atau berkomunikasi dengan mikrokontroler [28]. Cara konvensional untuk penggunaan tablet atau smartphone Android, adalah sebagai periferal USB yang terhubung ke host USB (misalnya $P C$ ) dan penyinkronan data dan file media. Perangkat berbasis Android juga dapat berperilaku sebagai host USB sejak level API 12 (Android versi
3.1). Penggunaan terhadap fitur tersebut, maka dapat dilakukan keterhubungan dengan mouse USB, keyboard, atau memory stick dengan smartphone Android [28]. Pemasangan secara fisis pada perangkat periferal, diperlukan kabel adaptor khusus yang disebut USB On The Go (USB OTG) [29,30]. Bentuk fisis paling umum, tercakup konektor USB tipe-A bentuk female di salah satu ujung tempat perangkat periferal tersambung dan konektor USB tipe micro bentuk male di ujung lain terhubung ke perangkat Android [27,28].

Arduino Ethernet shield [31], adalah papan mikrokontroler berdasarkan ATmega328 [12] dengan 14 pin masukan/keluaran (input/output) digital, 6 masukan analog diberi label A0-A5, osilator kristal 16 MHz., konektor RJ45, kabel koneksi ke catu daya, header In-Circuit Serial Programming (ICSP), dan tombol reset [13,23]. Keberadaan Internet Protocol (IP) telah secara aktual sebagai pembawa data, namun $I P$ ini telah serahkan penyampaian data tersebut kepada protokol lebih tinggi [32,2], yaitu Transmission Control Protocol (TCP) yang merupakan sebuah protokol standar sebagai pengatur segala pertukaran data. Keberadaan TCP merupakan upaya, agar setiap perangkat komputer dengan alamat IP (IP address) yang dapat diketahui dan dikenali, sehingga $I P$ ini dengan dua cakupan berupa source dan destination untuk Internet Protocol Address [31,2].

Secara khusus review terhadap penelitian sebelumnya [5,6,1], bahwa implementasi uji verifikasi berupa simulasi terhadap rangkaian terintegrasi berbantuan mikrokontroler (modul Arduino UNO R3) untuk pemantauan kondisi $M C B$ [5,6] dilakukan dengan bantuan aplikasi Proteus [33]. Pengukuran kinerja sistem minimum berbasis modul Arduino UNO R3, dan $W i-F i$, dilakukan dengan pemanfaatan jaringan $W i-F i$ melalui Wi-Fi Router, diperoleh hasil sesuai perancangan [1] untuk pemantauan dan pengendalian terhadap beban listrik (dipilih lampu pijar) pada analogi instalasi listrik fase-tiga. Perolehan bentuk fisis sistem pemantauan dan pengendalian terhadap lampu pijar pada analogi instalasi listrik fase-tiga, dilakukan melalui handshaking secara perangkat jeras dan lunak [1]. Integrasi sistem secara hardware, berupa integrasi sejumlah peranti elektronika, sedangkan integrasi sistem secara software berupa empat tahapan, yaitu (i) pemasangan Arduino IDE, penyusunan struktur program, dan proses compiling dan uploading, (ii) pemasangan dan pembuatan aplikasi pada komputer personal, dan (iii) pemasangan aplikasi dengan format apk pada smartphone Android. Mikrokontroler Arduino UNO R3 dan smartphone Android sebagai pusat kendali sistem pemantauan dan pengendalian untuk beban listrik berupa lampu pijar pada analogi instalasi listrik fase-tiga.

Berdasarkan sejumlah "state of the art" penelitian terkait, maka dilaksanakan sebuah penelitian melalui 
pembuatan unit kendali yang dapat diintegrasikan ke salah satu smart home system platform untuk pemantauan dan pengendalian tegangan listrik pada jaringan fase-tiga. Unit kendali berupa perangkat elektronika terintegrasi berbasis modul Arduino UNO
R3 dan Ethernet shield berbantuan Mikrotik RouterBoard. Diagram skematis sistem minimum untuk pemantauan dan pengendalian tegangan listrik pada analogi jaringan fase-tiga, seperti ditunjukkan pada Gambar 1.

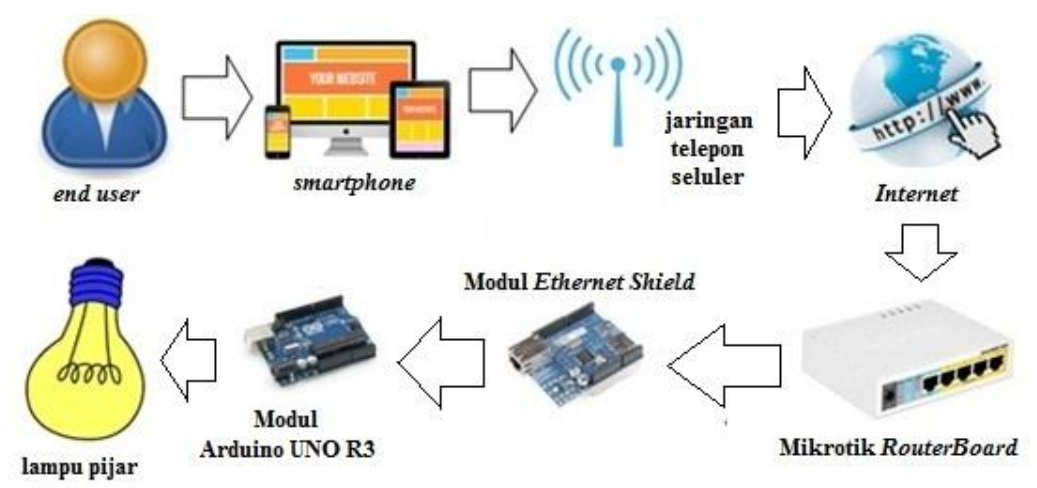

Gambar 1. Diagram skematis sistem minimum untuk pemantauan dan pengendalian tegangan listrik pada analogi jaringan fase-tiga

Berdasarkan Gambar 1 ditunjukkan, bahwa untuk keperluan pembuatan sistem pengendalian melalui jaringan Internet berbantuan board Arduino UNO R3 [13] dan Ethernet shield W5100 [31], perangkat MikroTik RouterBoard, dan smartphone Android [2], sehingga ditetapkan sasaran penelitian, yaitu: (1) membuat bentuk fisis sistem minimum berbasis mikrokontroler untuk pemantauan dan pengendalian tegangan jaringan listrik fase-tiga dan (2) mengukur kinerja sistem minimum untuk pemantauan dan pengendalian tegangan listrik melalui smartphone Android.

\section{Metode Penelitian}

Penyediaan sejumlah bahan penelitian merupakan dukungan terhadap pelaksanaan metode penelitian. Bahan penelitian berupa perangkat keras dan lunak. Perangkat keras, meliputi: (i) board Arduino UNO R3, (ii) modul Ethernet shield, (iii) sejumlah modul relai, (iv) sejumlah resistor dan transistor, (v) sejumlah kabel pin, (vi) breadboard, (vii) sejumlah adaptor, (viii) sejumlah lampu pijar, (ix) miniature circuits breakers $(M C B s)$, (x) catu daya (power supply), dan (xi) Mikrotik RouterBoard. Perangkat lunak berupa Arduino IDE versi 1.8.10 yang tersedia secara gratis dan dapat diperoleh secara langsung pada halaman resmi Arduino di https://www.arduino.cc/en/main/software, bahasa pemrograman $\mathrm{C}$, dan aplikasi online berbasis app inventor di http://ai2.appinvntor.mit.edu. Selain bahan penelitian, diperlukan alat-alat penelitian berupa: (a) web browser Google Chrome, (b) smartphone Android merek Samsung Note 3 SM-N900, (c) laptop Core2Duo P7370 2.00 GHz., dan (d) alat ukur terhadap tegangan listrik (voltmeter).

Pencapaian sasaran penelitian pertama tentang pembuatan bentuk fisis sistem minimum untuk pemantauan dan pengendalian tegangan lsitrik, dilakukan melalui (i) pengintegrasi sejumlah perangkat keras dan pemasangan Arduino IDE, (ii) pembuatan aplikasi monitoring berbasis app inventor pada komputer personal, dan (iii) pemasangan aplikasi monitoring pada smartphone Android. Sasaran penelitian kedua tentang pengukuran kinerja sistem minimum, dilakukan melalui pemantauan dan pengendalian tegangan listrik, berupa (i) pembuatan tampilan kebutuhan sistem hardware dan software untuk pelaksanaan pengamatan saat pemberian kondisi terhadap tegangan listrik pada analogi jaringan listrik fase-tiga dan (ii) pelaksanaan pemberian kondisi untuk pemantauan dan pengendalian terhadap tegangan listrik pada analogi jaringan fase-tiga. Diagram alir metode penelitian, seperti ditunjukkan pada Gambar 2.

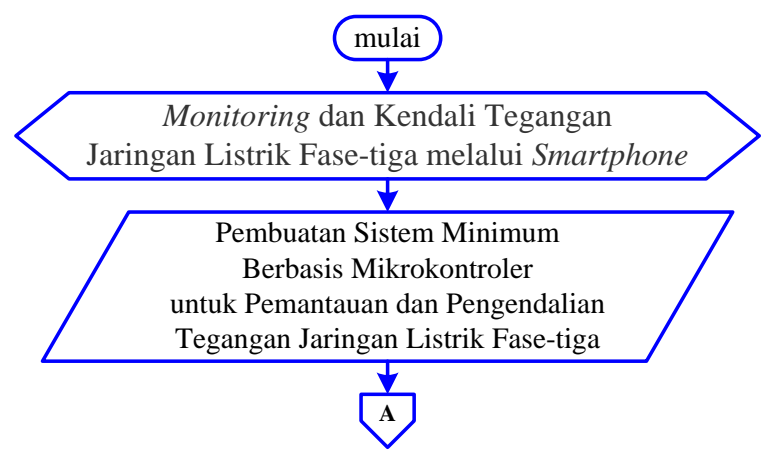

DOI: https://doi.org/10.29207/resti.v6i1.3662

Lisensi: Creative Commons Attribution 4.0 International (CC BY 4.0) 


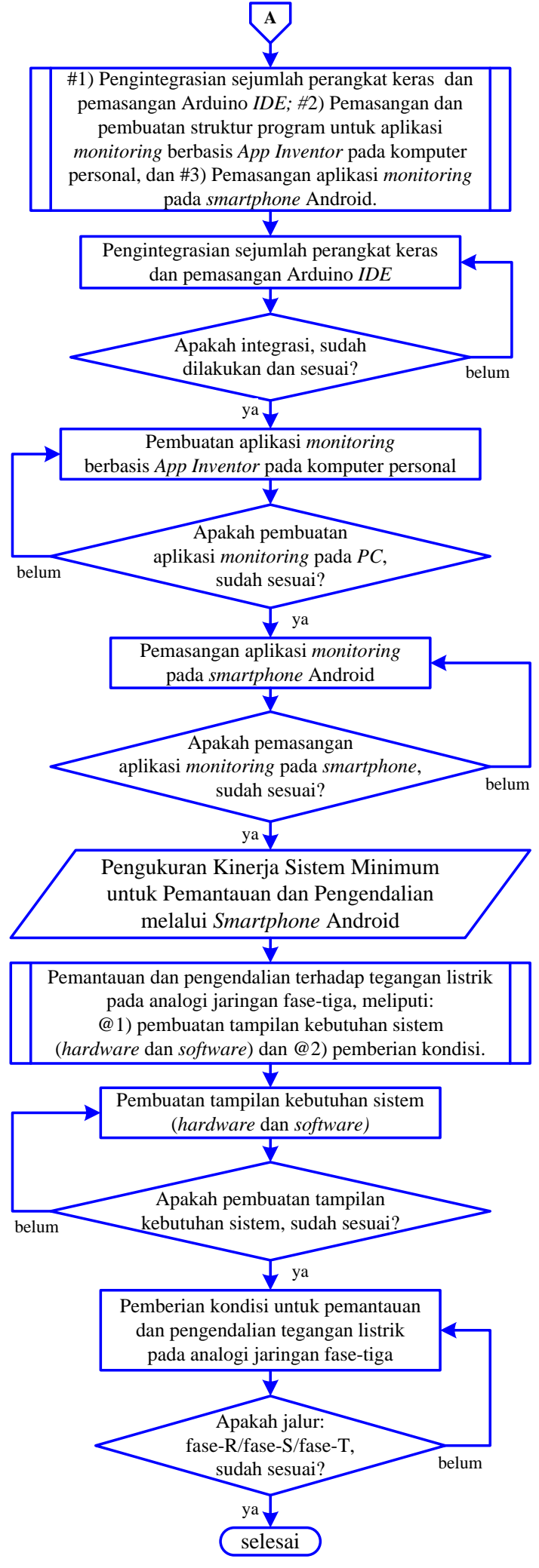

Gambar 2. Diagram alir metode penelitian

\section{Hasil dan Pembahasan}

3.1 Sistem Minimum Berbasis Mikrokontroler untuk Pemantauan dan Pengendalian Tegangan Jaringan Listrik Fase-tiga

Keterbentukan sebuah sistem minimum berbasis mikrokontroler digunakan untuk pemantauan dan pengendalian tegangan jaringan listrik fase-tiga. Proses pembentukan dilakukan melalui i) pengintegrasian sejumlah perangkat keras dan pemasangan perangkat lunak (software, aplikasi) Arduino atau Arduino IDE, ii) pemasangan dan pembuatan struktur program untuk aplikasi pemantauan (monitoring) berbasis App Inventor pada komputer personal, dan iii) pemasangan aplikasi monitoring pada smartphone Android.

Integrasi sejumlah perangkat keras dan pemasangan aplikasi Arduino IDE merupakan upaya untuk keterbentukan handshaking secara hardware dan software melalui sejumlah tahapan. Tahapan pertama berupa pengunduhan raw-file Arduino1.8.10 melalui web (www.arduino.cc). Aplikasi Arduino digunakan untuk proses compiling dan uploading struktur sintaks program untuk sistem minimum pemantauan terhadap analogi jaringan listrik fase-3. Tahapan dimulai dengan pengunduhan file dan pemasangan Arduino IDE versi 1.8.10. Setelah Arduino software terpasang pada $P C$ dilakukan langkah-langkah lanjutan, yaitu penentuan algoritma dan penulisan sintaks yang dilanjutkan dengan proses compiling dan uploading terhadap source code dari komputer personal (personal computer, $P C$ ) ke dalam mikrokontroler Arduino UNO R3. Pembuatan sintaks program untuk pemantauan sekaligus pengendalian tegangan listrik pada analogi jaringan listrik fase-tiga, berupa tahapan pengunggahan sintaks pada Arduino untuk pengaktifan modul Ethernet shield.

Algoritma dibuat berbentuk diagram alir yang dilanjutkan dengan penulisan sintaks berbasis bahasa pemrograman $C$. Penulisan sintaks merupakan upaya untuk perolehan sejumlah source code sebagai inti pengoperasian mikrokontroler Arduino UNO R3. Perolehan sebuah sistem pengendalian dengan source code berbasis bahasa $C$, merupakan salah satu bentuk minimalis sebuah sistem tertanam (embedded system). Diagram alir untuk pengaktifan ethernet shield dan pembuatan sintaks, seperti ditunjukkan pada Gambar 3.

Berdasarkan Gambar 3 ditunjukkan, bahwa pembuatan diagram alir berkenaan dengan permintaan pengalamatan IP secara Dynamic Host Control Protocol (DHCP) pada Mikrotik RouterBoard, sekaligus sebagai bentuk penetapan ethernet shield pada Mikrotik RouterBoard. Untuk kondisi dimana modul ethernet shield beroperasi dengan baik, maka IP tertampilkan pada monitor Arduino IDE, sedangkan jika kondisi modul ethernet shield terdapat masalah, maka tertampilkan error pada monitor Arduino IDE.

DOI: https://doi.org/10.29207/resti.v6i1.3662

Lisensi: Creative Commons Attribution 4.0 International (CC BY 4.0) 
Setelah penyelesaian susunan sintaks, diperlukan compiling pada Arduino IDE yang telah berisi script pengaktifan.

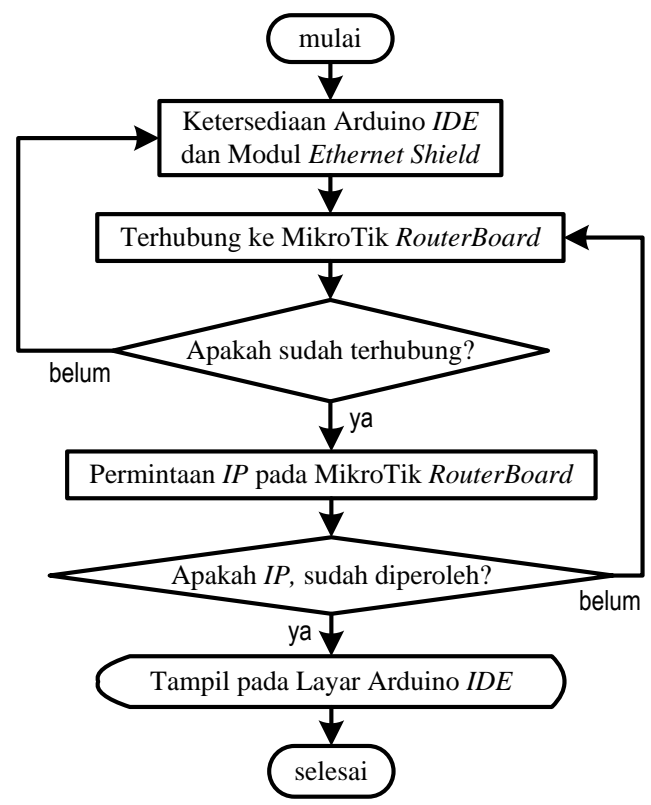

Gambar 3 Diagram alir untuk pengaktifan ethernet shield

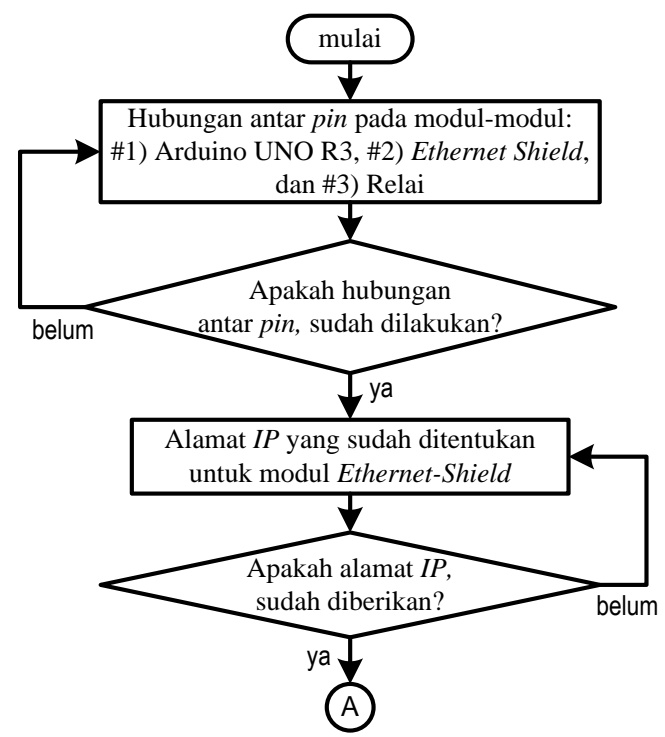

Pengaktifan modul Ethernet shield pada Arduino IDE, dilakukan melalui proses lanjutan berupa pembuatan source code tersebut, agar Arduino UNO R3 tersebut dapat berfungsi untuk pemantauan dan pengendalian kondisi terhadap analogi jaringan listrik fase-tiga. Tampilan penentuan algoritma untuk pemantauan dan pengendalian tegangan listrik pada analogi jaringan listrik fase-tiga, seperti ditunjukan pada Gambar 4.

Berdasarkan Gambar 4 ditunjukkan, bahwa pengaktifan beberapa pin, pengaktifan IP yang sudah diberikan oleh Mikrotik RouterBoard, dan pengaktifan tampilan web server melalui Arduino IDE yang digunakan pada sistem pemantauan dan pengendalian tegangan listrik pada analogi jaringan listrik fase-tiga.

Tahapan compiling dan uploading terhadap source code ke dalam modul Arduino UNO R3 merupakan tahapan setelah penentuan algoritma dan penulisan sintaks untuk perolehan sejumlah struktur sintaks program. Proses compiling dan uploading terhadap source code dari $P C$ ke dalam modul Arduino UNO R3 dengan bantuan kabel $U S B$.

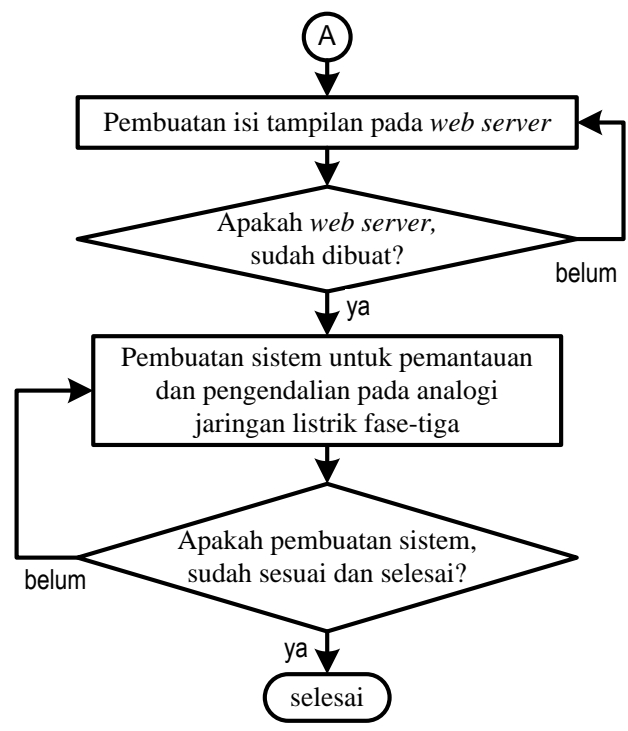

Gambar 4. Tampilan penentuan algoritma untuk pemantauan dan pengendalian tegangan listrik pada analogi jaringan listrik fase-tiga

Aplikasi monitoring berbasis app inventor digunakan pada komputer personal untuk pembuatan sistem pemantauan dan pengendalian terhadap tegangan listrik pada analogi jaringan fase-tiga. Pembuatan aplikasi monitoring dilakukan secara online melalui web browser (http://ai2.appinventor.mit.edu). Pembuatan aplikasi untuk pemantauan dan pengendalian tegangan listrik pada analogi jaringan listrik fase-tiga yang dipasang pada smartphone Android berbantuan app inventor, berupa aplikasi dengan ekstensi (.apk) yang sebelumnya telah di "build" melalui website app inventor yang secara otomatis file tersebut tersimpan pada $P C$ dan sudah siap untuk dipasang pada smartphone Android.

Pembuatan aplikasi dilakukan dengan layar design dan blocks pada komputer personal. Tampilan pembuatan aplikasi monitoring melalui app inventor dengan layar design pada komputer personal, sedangkan menu-menu pada layar blocks digunakan untuk pemberian perintahperintah dalam bentuk puzzle yang sudah disediakan sebagai keperluan aplikasi yang dibuat pada layar block. Pembuatan aplikasi monitoring dengan layar blocks pada komputer personal dapat dilakukan untuk pemakaian melalui langkah-langkah: )1)ketika aplikasi

DOI: https://doi.org/10.29207/resti.v6i1.3662

Lisensi: Creative Commons Attribution 4.0 International (CC BY 4.0) 
monitoring di'buka", maka tertampilkan hasil dari web server; (2) pada layar smartphone ditampilkan hasil dari web server berupa tabel, dimana tabel tersebut berisikan tabel fase yang digunakan sebagai pemantauan, tabel status digunakan sebagai pemantauan terhadap fase, tabel saklar digunakan sebagai button untuk pengendalian terhadap lampu, dan "volt" berupa informasi nilai tegangan yang masuk pada saat saklar diaktifkan; dan (3) refresh button digunakan untuk reloading isi dari web server.

Setelah pembuatan aplikasi monitoring pada web browser berbasis app inventor, maka dilakukan pengunduhan terlebih dahulu untuk pemasangan aplikasi monitoring dengan transfer data melalui komputer personal. Langkah lanjutan berupa pelaksanaan pengunduhan aplikasi berbasis App Inventor, diikuti langkah pemasangan aplikasi monitoring pada smartphone Android.

Perolehan hasil selanjutnya berupa pembukaan pada smartphone Android bermerek Samsung Note 3 SMN900. Tampilan hasil pemasangan aplikasi monitoring pada smartphone Android, seperti ditunjukkan pada Gambar 5.

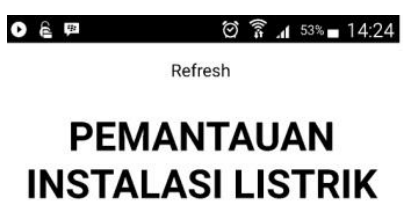

\begin{tabular}{|c|c|c|c|}
\hline FASE & STATUS & SAKLAR & VOLT \\
\hline $1(\mathrm{R})$ & PADAM & $\underline{\text { ON }}$ & 0.00 \\
\hline $2(\mathrm{~S})$ & PADAM & $\underline{\text { ON }}$ & 0.00 \\
\hline $3(\mathrm{~T})$ & PADAM & $\underline{\text { ON }}$ & 0.00 \\
\hline
\end{tabular}

Gambar 5. Tampilan hasil pemasangan aplikasi monitoring pada smartphone Android

Berdasarkan Gambar 5 ditunjukkan, bahwa tampilan hasil pemasangan aplikasi monitoring pada smartphone Android berupa 4 (empat) kolom dengan pencantuman (i) "fase", (ii) "status", (iii) "saklar", dan (iv) "volt".

\subsection{Kinerja Sistem Minimum untuk Pemantauan dan Pengendalian melalui Smartphone Android}

Kinerja sistem minimum untuk pemantauan dan pengendalian tegangan listrik pada analogi jaringan listrik fase-tiga dilakukan untuk perolehan hasil, setelah dilakukan uploading terhadap struktur program berbasis Arduino $I D E$ dari $P C$ ke modul Arduino UNO R3 dan pembuatan aplikasi monitoring untuk smartphone Android, selanjutnya diperoleh tampilan kebutuhan sistem sebagai tahapan pelaksanaan pengamatan saat pemberian kondisi terhadap masing- masing jalur fase pada analogi jaringan listrik fase-tiga, jalur fase-R atau fase-S atau fase-T.

Dua kebutuhan sistem untuk pengamatan pada langkah pemantauan dan pengendalian terhadap tegangan listrik pada analogi jaringan fase-tiga, yaitu tampilan kebutuhan sistem untuk hardware dan software. Diagram blok tampilan sistem secara hardware, seperti ditunjukkan pada Gambar 6.

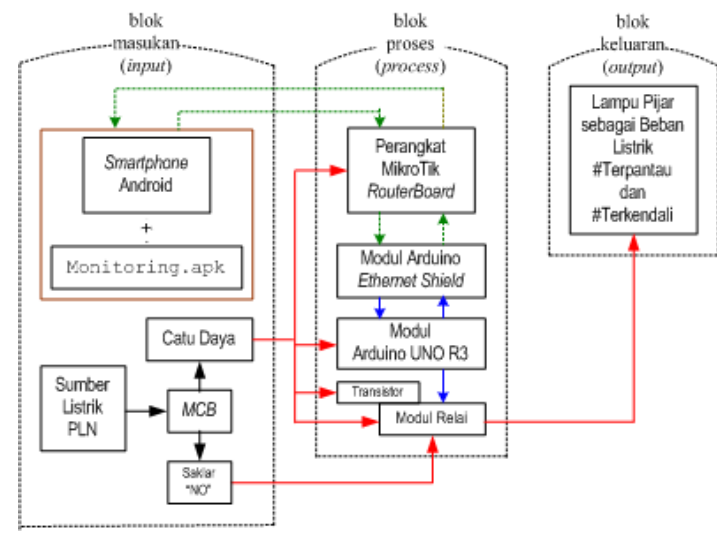

Gambar 6 Diagram blok tampilan sistem secara hardware

Berdasarkan Gambar 6 ditunjukkan, bahwa bread board digunakan untuk tampilan sistem secara hardware berbantuan kabel jumper secukupnya dengan tujuan untuk kemudahan proses pembuatan dan simulasi untuk penghubungan komponen satu dengan yang lain melalui penancapan kabel jumper pada jalur yang sudah disediakan, sehingga diperoleh kemudahan dalam proses perlepasan saat terjadi kesalahan teknis atau trouble.

Penggunaan smartphone Android untuk penelitian ini, yaitu Samsung Note 3 SM-N900, RAM 3 GB, Android versi 5.0 Lollipop. Keberadaan diagram blok sistem secara hardware berupa tiga blok yang meliputi (a) blok masukan, (b) blok proses, dan (c) blok keluaran. Blok masukan terdiri atas 5 (lima) jalur untuk (i) smartphone Android, (ii) aplikasi monitoring.exe sebagai sistem pengoperasian pemantauan dan pengendalian pada analogi jaringan listrik fase-tiga, (iii) catu daya (power supply) sebagai pencatu untuk modul Arduino UNO R3, (iv) sumber listrik PLN sebagai pencatu daya pada minimum system dan analogi jaringan listrik fase-3, dan (v) $M C B$ sebagai pengaman dan pemutus/penghubung lampu dari sumber listrik PLN. Blok proses terdiri atas 4 (empat) jalur yang meliputi (i) Mikrotik RouterBoard untuk jalur smartphone Android, agar dapat terhubung ke web server, (ii) Ethernet shield untuk jalur modul Arduino UNO R3, agar dapat terhubung ke Mikrotik RouterBoard, (iii) Arduino UNO R3, perangkat utama pada sistem untuk compiling dan uploading, agar sistem beroperasi secara sempurna, dan (iv) modul relai sebagai perangkat pendukung, agar modul Arduino dapat digunakan untuk pengendalian lampu pijar. Blok keluaran hanya terdiri atas satu komponen, yaitu lampu

DOI: https://doi.org/10.29207/resti.v6i1.3662

Lisensi: Creative Commons Attribution 4.0 International (CC BY 4.0) 
pijar sebagai penanda, apakah kondisi sistem telah beroperasi dengan baik atau terdapat trouble.

Diagram blok untuk tampilan sistem secara software, seperti ditunjukkan pada Gambar 7.

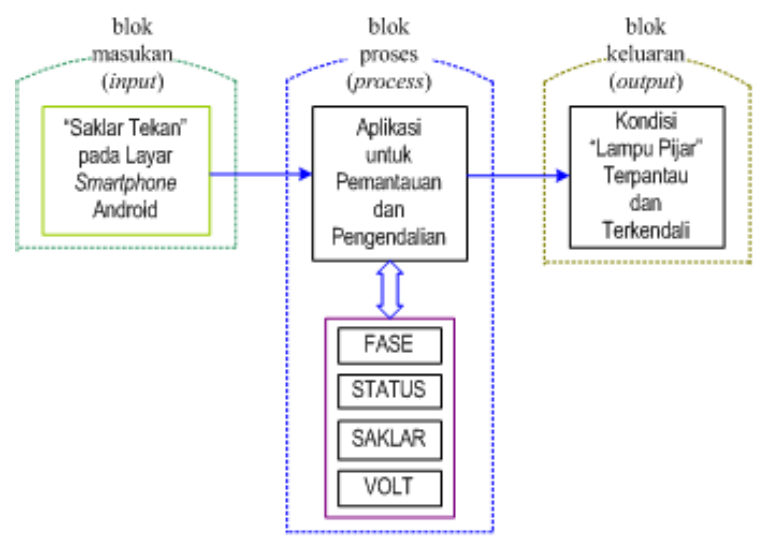

Gambar 7 Diagram blok untuk tampilan sistem secara software

Berdasarkan Gambar 7 ditunjukkan, bahwa software yang digunakan pada smartphone Android dirancang melalui sebuah aplikasi berbasis web, yaitu http//ai2.appinventor.mit.edu. Aplikasi berbasis web tersebut dikhususkan untuk pengembangan dan pembuatan aplikasi berbasis Android. Dalam aplikasi tersebut digunakan sebuah laptop dengan minimal spesifikasi pada processor Core2Duos P7370, CPU $2.00 \mathrm{GHz}$. dan RAM 2 GB dengan sistem pengoperasian Windows 7 Ultimate 32-Bit. Untuk akses aplikasi berbasis web http//ai2.appinventor.mit.edu digunakan sebuah browser Google Chrome dengan versi 58.0.3029.110, sedangkan untuk keterhubungan dengan Internet digunakan Mikrotik RouterBoard. Blok diagram pada sistem secara software berjumlah tiga buah, yaitu: a) blok masukan, b) blok proses, dan c) blok keluaran.

Blok input hanya terdapat 1 (satu) jalur, yaitu push button untuk refresh atau reolad ulang pada saat webserver dalam keadaan error. Blok process pada sistem secara software berupa tampilan hasil web server pada aplikasi monitoring.exe, dimana terdapat beberapa tabel, yaitu (i) "fase" berfungsi sebagai suatu informasi, (ii) "status" digunakan sebagai informasi sistem pemantauan dan pengendalian pada analogi jaringan listrik fase-tiga, (iii) "saklar" digunakan untuk pengendalian jalur fase pada lampu, dan (iv) "volt" sebagai tampilan informasi nilai tegangan yang dihasilkan pada saat jalur fase dengan lampu dalam keadaan berpijar. Blok output hanya terdapat satu jalur, yaitu kondisi "lampu" sebagai penanda, apakah aplikasi yang dibuat beroperasi dengan baik atau terjadi trouble.

Pelaksanaan pemberian kondisi untuk pemantauan dan pengendalian tegangan listrik pada analogi jaringan listrik fase-tiga (fase-R, fase-S, fase-T) dilakukan setelah perolehan tampilan sistem secara hardware dan software. Tampilan pengendalian lampu pijar pada analogi jaringan listrik fase-tiga, berupa urutan hasil pengamatan, yaitu pengaktifan pada fase- $R$, fase-S, dan fase-T.

\section{\#1) Pengaktifan pada jalur fase-R}

Saat tanda "saklar" pada smartphone Android ditekan untuk pengaktifan lampu pijar pada fase-R, sesaat kemudian lampu pada fase-R menyala. Tampilan hasil pengamatan terhadap pengendalian lampu pijar jalur fase-R, seperti ditunjukkan pada Gambar 8.

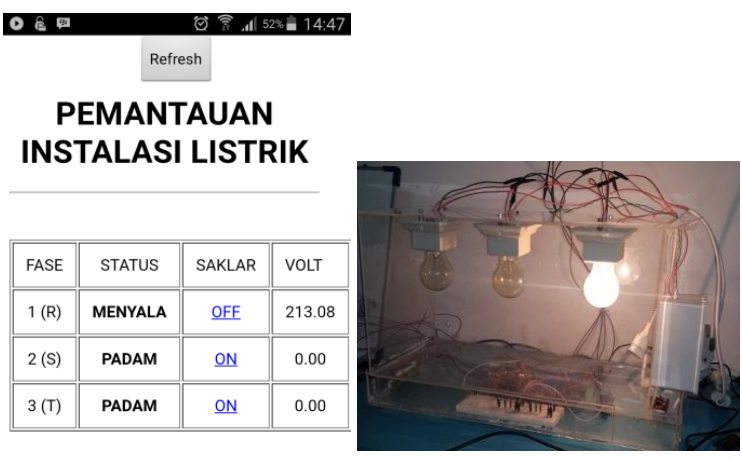

Gambar 8. Tampilan hasil pengamatan terhadap pengendalian lampu pijar jalur fase-R

Berdasarkan Gambar 8 dapat dijelaskan, bahwa lampu pijar pada fase-R telah berpijar, sedangkan lampu pijar pada fase-S dan fase-T tidak berpijar (masih padam).

\section{\#2) Pengaktifan pada jalur fase-S}

Saat tanda "saklar" pada smartphone Android ditekan untuk pengaktifan lampu pijar pada fase-S, sesaat kemudian lampu pijar pada fase-S berpijar. Tampilan hasil pengamatan terhadap pengendalian lampu pijar jalur fase-S, seperti ditunjukkan pada Gambar 9.

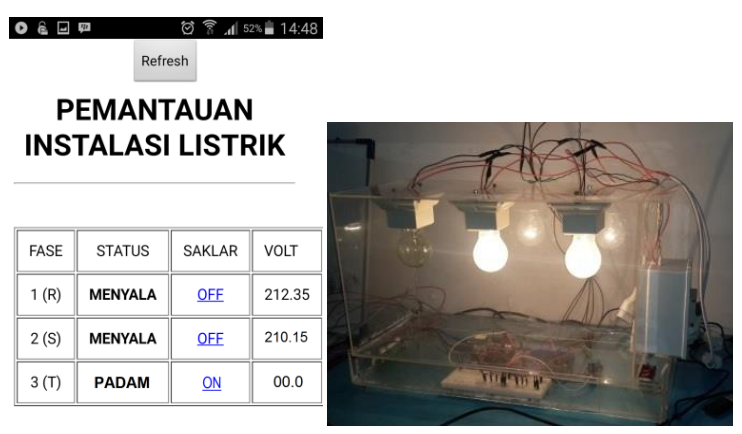

Gambar 9. Tampilan hasil pengamatan terhadap pengendalian lampu pijar jalur fase-S

Berdasarkan Gambar 9 dapat dijelaskan, bahwa lampu pijar pada fase-R masih berpijar dan lampu pijar pada fase-S telah berpijar, sedangkan lampu pijar pada faseT tidak berpijar.

\section{\#3) Pengaktifan pada jalur fase-T}

Saat tanda "saklar" pada smartphone Android ditekan untuk pengaktifan lampu pijar pada fase-T, sesaat kemudian lampu pijar pada fase-T berpijar. Tampilan 
hasil pengamatan terhadap pengendalian lampu pijar jalur fase-T, seperti ditunjukkan pada Gambar 10.

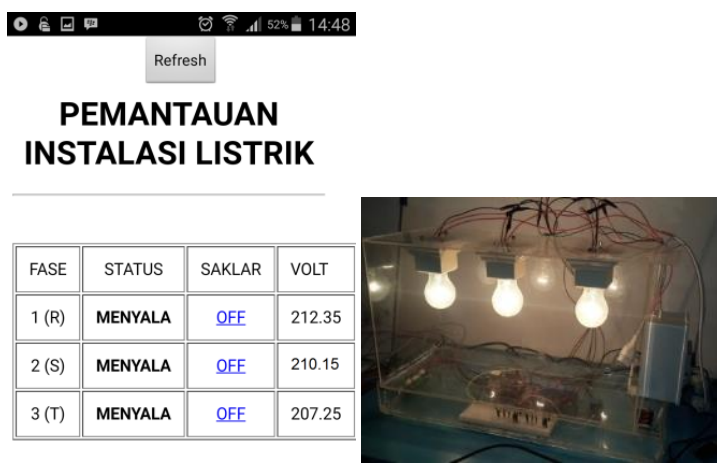

Gambar 10. Tampilan hasil pengamatan terhadap pengendalian lampu pijar jalur fase-T

Berdasarkan Gambar 10 dapat dijelaskan, bahwa lampu pijar pada fase-R dan fase-S masih berpijar, sedangkan lampu pijar pada fase-T juga telah berpijar.

Setiap baris fase-R/fase-S/fase-T, terdapat kolom "status" berfungsi sebagai informasi pemantauan analogi jaringan listrik terhadap setiap fase. Untuk kondisi dimana saklar ditekan ON, maka keadaan status lampu pijar berubah dari kondisi padam menjadi menyala dan berlaku untuk sebaliknya. Kolom "saklar" berfungsi sebagai pengendalian analogi jaringan listrik setiap fase. Kolom "volt" berfungsi sebagai informasi nilai tegangan pemantauan pada analogi jaringan listrik setiap fase. Untuk kondisi dimana saklar ditekan ON, maka pada kolom "volt" berisikan nilai tegangan dan berlaku untuk sebaliknya.

\section{Kesimpulan}

Kesimpulan ditetapkan yang berpedoman kepada sasaran penelitian, bahwa perakitan untuk keterbentukan sebuah sistem minimum secara hardware yang dilengkapi dengan pemasangan aplikasi format apk pada smartphone Android. Keberadaan tampilan pada smartphone Android untuk pengukuran kinerja minimum system didasarkan kepada 2 (dua) kebutuhan sistem, yaitu secara hardware dan software, sehingga proses pemantauan dan pengendalian terhadap tegangan listrik pada analogi jaringan listrik fase-tiga, melalui 3 (tiga) pemberian perintah pengaktifan pada masing-masing jalur fase-R, fase-S, dan/atau fase-T. Pemantauan dan pengendalian dengan pemberian kondisi telah sesuai dengan keberadaan dan fungsi pembuatan minimum system.

Saran untuk penelitian lanjutan terkait dengan pembuatan berbagai unit kendali yang kelak dapat dijadikan bagian terintegrasi pada smarthome system platform berbasis wireless sensor network (WSN) dan Internet of Things (IoT).

\section{Daftar Rujukan}

[1] A. Goeritno, F. Hendrian, dan Ritzkal. (2019, Desember). Pengendalian Lampu Pijar pada Analogi Jaringan Listrik FaseTiga melalui Smartphone Berbasis Android Berbantuan Jaringan Wi-Fi. Jurnal Ilmiah SETRUM. [Online]. 8(2), hlm. 274-286. Tersedia: http://jurnal.untirta.ac.id/index.php/jis/article/view/6977/pdf_ 62

[2] E. Dainow, Understanding Computers, Smartphones and the Internet, 1st ed. Toronto, CA: CreateSpace, 2018.

[3] K.M. Deepashri, P.B. Sachidanand, and H.S. Latha. (2018). Industrial Appliances Control Using Android Mobile and Bluethooth Technology. International Journal of Engineering and Manufacturing Science. [Online]. 8(1), 33-42. Available: https://www.ripublication.com/ijems_spl/ijemsv8n1_04.pdf

[4] A.E. Amoran, A.S. Oluwole, E.O. Fagorola, \& R.S. Diarah. (2021). Home automated system using Bluetooth and an android application. Scientific African. [Online]. 11(e00711), pp. 1-11. Available: http://dx.doi:10.1016/j.sciaf.2021.e00711

[5] A. Johan, A. Goeritno, dan Ritzkal, "Prototipe Sistem Elektronis Berbasis Mikrokontroler Untuk Pemantauan Jaringan Listrik," di Prosiding SNTI V-2016, Jakarta, JK, 2016, hlm. 324-330.

[6] A. Goeritno, Ritzkal, dan A. Johan. (2016, Desember). Kinerja Prototipe Sistem Elektronis Berbasis Mikrokontroler Arduino Uno R3 Untuk Pemantauan Analogi Jaringan Listrik. Jurnal Ilmiah SETRUM. [Online]. 5(2), hlm. 94-99. Tersedia: https://jurnal.untirta.ac.id/index.php/jis/article/view/971/772

[7] A. Goeritno, dan Y. Herutama, "Prototipe Sistem Elektronis Berbantuan PC untuk Pemantauan Kondisi Pasokan Daya Listrik," Jurnal Rekayasa Elektrika, vol.14, no.2, Agustus 2018, hlm. 96-104. http://dx.doi.org/10.17529/jre.v14i2.10904

[8] R. Effendi, A. Goeritno, dan R. Yatim. (2015, November). Prototipe Sistem Pendeteksian Awal Pencemaran Air Berbantuan Sensor Konduktivitas dan Suhu Berbasis Mikrokontroler. Prosiding Semnastek ke-2 (hlm. (TE-017) 16). FT UMJ. [Online]. Tersedia: https://jurnal.umj.ac.id/index.php/semnastek/article/view/430/ 396.

[9] I. Mustofa, A. Goeritno, dan B.A. Prakosa, "Prototipe Sistem Kontrol Berbasis Mikrokontroler untuk Pengaman terhadap Gangguan Hubung Singkat pada Otobis," di Prosiding SNTI V2016, Jakarta, JK, 2016, hlm. 317-323.

[10] Sopyandi, A. Goeritno, dan R. Yatim, "Prototipe Sistem Pengontrolan Berbasis Payload Data Handling Berbantu Mikrokontroler untuk Instalasi Listrik Rumah Tinggal," di Prosiding SNTI V-2016, Jakarta, JK, 2016, 331-337.

[11] B.A. Prakoso, A. Goeritno, dan B.A. Prakosa, "Prototipe Sistem Pengontrolan Berbasis Mikrokontroler ATmega32 untuk Analogi Smart Green House," di Prosiding SNTI V-2016, Jakarta, JK, 2016, hlm. 338-345.

[12] ATMEL Corporation. (2016). 8-bit AVR Microcontroller ATmega32A Datasheet Complete. [Online]. Available: http://www.atmel.com/Images/Atmel-8155-8-bitMicrocontroller-AVR-ATmega32A_Datasheet.pdf

[13] M. Banzi and M. Shiloh, Getting Started with Arduino: the Open Source Electronics Prototyping Platform. $3^{\text {rd }}$ ed. Sebastopol, CA: Maker Media, 2015, pp. 15-22.

[14] Suhendri, dan A. Goeritno, "Pemantauan Energi Listrik pada Satu kWH-meter Fase Tunggal untuk Empat Kelompok Tegangan Berbasis Metode Payload Data Handling," Jurnal Rekayasa Elektrika, vol. 14, no. 3, hlm. 189-197, Desember 2018. http://dx.doi.org/10.17529/jre.v14i3.11952

[15] I. Setyawibawa, dan A. Goeritno. (2019, April). Communication Interface Adapter Berbasis Mikrokontroler Arduino Terkendali Sinyal Dual Tone Multi Frequency. Jurnal ELKHA. [Online]. 11(1), hlm. 19-26. Tersedia: http://jurnal.untan.ac.id/index.php/Elkha/article/view/30374/7 5676581006

[16] D. Suhartono, dan A. Goeritno. (2019, April). Prototipe Sistem Berbasis Mikrokontroler untuk Pengkondisian Suhu pada Analogi Panel dengan Analogi Sistem Air Conditioning,

DOI: https://doi.org/10.29207/resti.v6i1.3662

Lisensi: Creative Commons Attribution 4.0 International (CC BY 4.0) 
Jurnal EECCIS (Electrics, Electronics, Communications, Controls, Informatics, Systems). [Online]. 13(1), hlm. 22-30. Tersedia:

https://jurnaleeccis.ub.ac.id/index.php/eeccis/article/view/554 1345

[17] H.A. Fazry dan A. Goeritno. (2020, Desember). Sistem Minimum dengan Battery Back-up Berbasis Mikrokontroler Arduino Untuk Pengoperasian Inkubator, Jurnal Ilmiah SETRUM. [Online]. 9(2), 113-126. Tersedia: https://jurnal.untirta.ac.id/index.php/jis/article/view/9458/pdf -86

[18] Darussalam, dan A. Goeritno. (2021, April). Pemanfaatan RFID, Loadcell, dan Sensor Infrared Untuk Miniatur Penukaran Botol Plastik Bekas, Jurnal RESTI. [Online]. 5(2), hlm. 281-291. https://doi.org/10.29207/resti.v5i2.3048

[19] F. Hendrian, Ritzkal, dan A. Goeritno. "Penggunaan Protokol Internet untuk Sistem Pemantauan pada Analogi Jaringan Listrik Fase-3 Berbantuan Mikrokontroler Arduino UNO R3 Terkendali melalui Smartphone Berbasis Android," di Prosiding SNSRT UPH-2017, Tangerang, BT, 2017, hlm. (II) $103-110$.

[20] A. Goeritno, F. Hendrian, dan Ritzkal. (2017, Juli). Lampu Pijar pada Analogi Jaringan Listrik Fase-Tiga Terkendali melalui Smartphone Berbasis Android Terhubung Internet Berbantuan Mikrokontroler. Prosiding SNATIF ke-4 (hlm. 45-62), FTUMK. [Online]. Tersedia: http://jurnal.umk.ac.id/index.php/SNA/article/view/1243/861.

[21] A.F. Nasyarudin, Ritzkal, dan A. Goeritno. "Prototipe Perangkat untuk Pemantauan dan Pengendalian Berbasis Web Diiintegrasikan ke Smarthome System," Indonesian Journal of Electronics and Instrumentations Systems (IJEIS), vol. 10, no. 2, 2020, hlm. 167-178. https://doi.org/10.22146/ijeis.58316.

[22] L. Hardian dan A. Goeritno. (2021). Pabrikasi Unit Kontrol Berbasis Web pada Smarthome System untuk Pengoperasian Pintu Gerbang. Jurnal RESTI (Rekayasa Sistem dan Teknologi Informasi). [Online]. 5(1), hlm. 163-173. https://doi.org/10.29207/resti.v5i1.2879.

[23] Arduino. Install the Arduino Software (IDE) on Window PCs. [Online].
https://www.arduino.cc/en/Guide/Windows

(accessed: December 24, 2019).

[24] T. Hamed, R. Dara, and S.C. Kremer. (2017). Intrusion Detection in Contemporary Environments. Computer and Information Security Handbook, 109-130. doi:10.1016/b978-0-12803843-7.00006-5

[25] Z. Miftah. (2019). Penerapan Sistem Monitoring Jaringan dengan Protokol SNMP pada Router Mikrotik dan Aplikasi Dude Studi Kasus STIKOM CKI. Faktor Exacta, [Online]. 12(1), hlm. 58-66. Tersedia: https://journal.lppmunindra.ac.id/index.php/Faktor_Exacta/art icle/viewFile/3481/2489.

[26] C. Hermawan, B.A. Prakosa, A.H. Hendrawan, dan A. Goeritno. "Penggunaan Protokol Internet dan Bluetooth Untuk Sistem Penggerakan Kunci Pintu Berbantuan Arduino UNO R3 Terkendali melalui Smartphone Berbasis Android 4.4.2 KitKat," di The 4th NCIEE, Cilegon, BT, 2016, hlm. 113-124.

[27] H. Zhong, "An Empirical Study on API Usages," Journal of Latex Class Files, vol.14, no.8, August 2015, pp. 1-14.

[28] H. Zhong, N. Meng, Z. Li, and L. Jia. "An Empirical Study on API Parameter Rules," in ICSE'20: 42th International Conference on Software Engineering (ICSE), Seoul, South Korea, $27^{\text {th }}$ June- $19^{\text {th }}$ July 2020 , pp. 1-13.

[29] USB Implementers Forum, Inc. (2011, July 14). USB On-TheGo and Embedded Host Automated Compliance Plan. (Revision $\quad 1.0 \quad$ r0.8.) [Online]. Available: http://www.usb.org/developers/onthego/otgeh_compliance_pl an_1_0.pdf

[30] MICROCHIPS. (2021). USB Cables and Connectors. Chandler, AZ: Microchip Technology, Inc. https://microchipdeveloper.com/usb:connectors

[31] Arduino. Arduino Ethernet Shield V1. [Online] Available: https://www.arduino.cc/en/Main/ArduinoEthernetShieldV1

[32] B.A. Forouzan. TCP/IP Protocol Suite, Fifth Edition. New York, NY: McGraw-Hill, 2013, pp. 7-8.

[33] Z-J. Cai, S-B. Tong. (2017). Application of Proteus Simulation Software in the Teaching of Electric Courses. 2017 4th ERMM, [Online].

Available: https://doi.org/10.12783/dtssehs/ermm2017/1472 